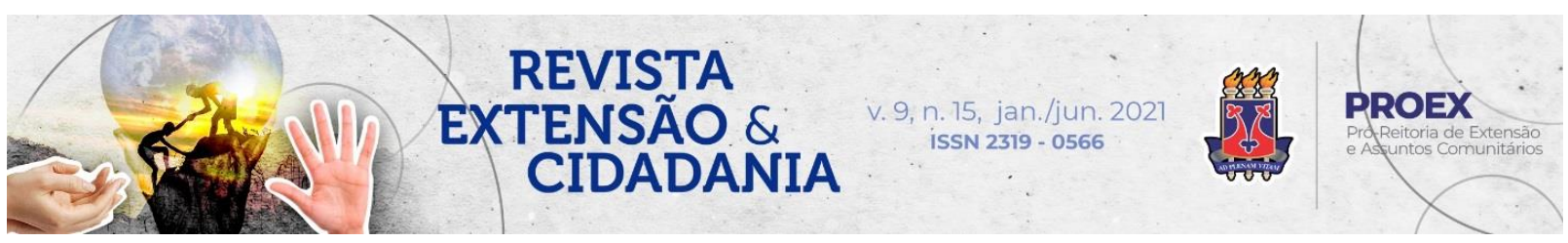

DOI: $10.22481 /$ recuesb.v9i15.8638

\title{
PERCEPÇÕES DA APLICAÇÃO DO PROJETO “EMPODERAMENTO FEMININO ATRAVÉS DA GERAÇÃo DE RENDA PELAS VENDAS”
}

\author{
Perceptions of the application of the project "Female empowerment through the income \\ generation by sales"
}

Claudia Almerinda de Souza Oliveira ${ }^{1}$
Kamili Oliveira Santana

Resumo: O artigo apresenta o projeto de extensão realizado no campus IFSP-Pirituba denominado "Empoderamento Feminino através da geração de renda pelas vendas". A proposta do projeto era atender um grupo de 25 mulheres acima de 16 anos com pouca ou nenhuma escolaridade em condições de vulnerabilidade social para capacitação profissional através do curso de Formação Inicial e Continuada (FIC), de Promotora de vendas e outras ações de extensão como palestras, oficinas e minicursos voltados ao empoderamento feminino, tornando a mulher consciente de seu papel na sociedade, das políticas públicas que podem atendê-la e também ser multiplicadora desses conhecimentos para mulheres que estejam em condições semelhantes a ela. O projeto contou com a parceria da ONG PAC - Projetos Amigos das Crianças e do Sebrae Pirituba. Do grupo inicial, 16 discentes concluíram o curso e conseguiuse verificar as características do público sendo majoritariamente composto por mulheres que se autodeclaram pardas ou negras, com renda mensal familiar inferior a 2 salários-mínimos e sem uma atividade remunerada. Com a realização do curso, houve uma mudança significativa da percepção do papel que ela desempenha na sociedade, da união entre elas, pela similaridade de suas condições e o mais importante foi o fortalecimento dos vínculos e a criação de uma rede

\footnotetext{
${ }^{1}$ Engenheira de produção; Mestra em Engenharia Elétrica, pela Universidade de São Paulo - USP; Professora do Instituto Federal de Educação, Ciência e Tecnologia de São Paulo - IFSP, Campus Pirituba, São Paulo-SP, Brasil. Orcid: 0000-0002-1508-0977 E-mail: csoliveira@ifsp.edu.br

2 Tecnóloga em Biocombustíveis; Mestra em Biotecnologia, pela Universidade Estadual Paulista - UNESP. Assistente de alunos do Instituto Federal de Educação, Ciência e Tecnologia de São Paulo - IFSP, Campus Pirituba, São Paulo-SP, Brasil. Orcid: 0000-0002-7926-0213 E-mail: kamili.santana@ifsp.edu.br

${ }^{3}$ Analista de Sistemas; Mestre e Doutor em Engenharia Biomédica, pela Universidade de Mogi das Cruzes UMC. Professor do Instituto Federal de Educação, Ciência e Tecnologia de São Paulo - IFSP, Campus Pirituba, São Paulo-SP, Brasil. Orcid: 0000-0002-0404-4807 E-mail: felipe.basile@ifsp.edu.br

${ }^{4}$ Cientista da computação; Doutor em Engenharia Elétrica pelo Centro Universitário FEI. Professor do Instituto Federal de Educação, Ciência e Tecnologia de São Paulo - IFSP, Campus Pirituba, São Paulo-SP, Brasil. Orcid: 0000-0003-2140-0129 E-mail: thiagohomem@ifsp.edu.br
} 
de apoio entre elas. E, para a equipe que participou do projeto, houve a constatação do significado de uma ação efetiva de extensão com a comunidade pela união de docentes, técnicos administrativos e discentes dos cursos do campus.

Palavras-chave: Empoderamento. Capacitação. Renda. Vendas. Extensão. Inclusão Digital.

\begin{abstract}
The article presents the extension project carried out on the IFSP-Pirituba campus called "Female Empowerment through the generation of income from sales". The project's proposal was to serve a group of 25 women over 16 years of age with little or no education in conditions of social vulnerability for professional training through the Sales Promoter initial and continuing training course (FIC) and other extension actions such as lectures, workshops and mini-courses focused on female empowerment, making women aware of their role in society, of public policies that can serve them and also to multiply this knowledge for women who are in similar conditions to her. The project had the partnership of the NGO PAC - Child Friendly Projects and Sebrae Pirituba. Of the initial group, 16 students completed the course, and it was possible to verify the characteristics of the public, being mostly composed of women who declare themselves to be brown or black, with a monthly family income of less than 2 minimum wages and without a paid activity. With the realization of the course, there was a significant change in the perception of the role it plays in society, of the union between them, due to the similarity of their conditions and the most important was the strengthening of bonds and the creation of a support network between them. For the team that participated in the project, the realization of the meaning of an effective extension action with the community through the union of teachers, administrative technicians, and students of the campus courses.
\end{abstract} Keywords: Empowerment. Training. Income. Sales. Extension. Digital inclusion.

\title{
Introdução
}

O papel ocupado pela mulher no mercado de trabalho nunca foi de muito destaque e, segundo a Organização Internacional do Trabalho (OIT), elas estão menos propensas a participar do que os homens e têm mais chances de estarem desempregadas na maior parte dos países do mundo, sendo a taxa de desemprego global das mulheres, em 2018, em 6\%, tendo que para cada 10 homens empregados, apenas 6 mulheres estão empregadas (OIT, 2018).

As mulheres são maioria na ocupação de postos de trabalho voltados em geral para atividades domésticas e serviços de limpeza e apresentam um nível de exclusão digital mais elevado que os homens nas camadas mais pobres da população. A maioria acaba não tendo oportunidade de utilizar computador, enquanto os homens acabam convivendo em ambientes que incentivam e permitem o conhecimento dos usos básicos do computador (SORJ et al., 2005). O dado é confirmado pelo Ministério do Trabalho no Brasil, que aponta o crescimento da ocupação feminina em postos formais de trabalho de 40,8\%, em 2007, para 44\%, em 2016.

Revista Extensão \& Cidadania, v. 9, n. 15, p. 46-63, jan./jun. 2021.

ISSN 2319-0566 DOI: 10.22481/recuesb.v9i15.8638 
A renda dessas trabalhadoras também tem ganhado cada vez mais importância no sustento das famílias; os lares brasileiros estão sendo chefiados por mulheres.

Em 1995, 23\% dos domicílios tinham mulheres como pessoas de referência, 20 anos depois, esse número chegou a 40\%. Cabe ressaltar que as famílias chefiadas por mulheres não são exclusivamente aquelas nas quais não há a presença masculina: em 34\% delas, havia a presença de um cônjuge. Embora haja um aumento percentual nos postos de trabalho, estes dados não condizem com o percentual de mulheres na população brasileira que são de 51,03\%, segundo o Instituto Brasileiro de Geografia e Estatística (IBGE) (PORTAL BRASIL, 2015).

Apesar dessas melhoras, as mulheres ainda ganham em média menos do que os homens, mesmo tendo mais tempo de estudo e qualificação. Segundo Paradella (2019), a taxa de desemprego subiu para 12,4\%, representando a entrada de 892 mil pessoas da população em estado de desemprego, afetando mais mulheres que homens. Dos desempregados 43,8\% (40,8 milhões) são mulheres, enquanto 56,2\% (52,1 milhões) são homens. Além disso, mesmo após uma leve queda na desigualdade salarial entre 2012 e 2018, mulheres ainda ganham em média, 20,5\% menos que os homens no Brasil. O IBGE estima o rendimento médio mensal dos homens em $\mathrm{R} \$ 2.306,00$, o das mulheres cai para $\mathrm{R} \$ 1.764,00$.

O estudo realizado pela OIT, Perspectivas Sociais e de Emprego no Mundo Tendências para Mulheres 2017, aponta que se houver um aumento da presença feminina no mercado de trabalho, pode-se injetar $\mathrm{R} \$ 382$ bilhões na economia brasileira, gerando $\mathrm{R} \$ 131$ bilhões às receitas tributárias. Mas para se chegar a este número, o Brasil precisa reduzir, até 2025, em pelo menos $25 \%$ a desigualdade na taxa de presença das mulheres no mundo do trabalho (MATA, 2012).

O estudo da OIT também mostra que as mulheres enfrentam desigualdades significativas na qualidade do emprego que possuem, tendo o dobro de chances de serem trabalhadoras familiares não remuneradas, significando que elas contribuem para um negócio familiar voltado para o mercado, muitas vezes sujeitas a condições de emprego vulneráveis, sem contratos escritos, respeito pela legislação trabalhista ou acordos coletivos. Enquanto nos países emergentes a participação das mulheres entre trabalhadores familiares não remunerados diminuiu na última década, nos países em desenvolvimento ela continua alta, representando $42 \%$ do emprego feminino, em 2018, em comparação com $20 \%$ do emprego masculino, e sem sinais de melhoria até 2021. Como resultado, há mais mulheres no emprego informal nos países

Revista Extensão \& Cidadania, v. 9, n. 15, p. 46-63, jan./jun. 2021.

ISSN 2319-0566 DOI: 10.22481/recuesb.v9i15.8638 
em desenvolvimento. Estes resultados confirmam pesquisas anteriores da OIT, que alertam sobre desigualdades significativas de gênero em relação a salários e proteção social.

Verifica-se que a desigualdade salarial ou outras formas de discriminação precisam ser minimizadas com a implementação de políticas públicas adaptadas às mulheres, levando em conta também as demandas desiguais que elas enfrentam em relação a responsabilidades domésticas e de cuidados de outros membros da família, que visem à qualificação, à capacitação e ao empoderamento das mulheres. Isso traz à tona um dos objetivos dos institutos federais: "estimular e apoiar processos educativos que levem à geração de trabalho e renda e à emancipação do cidadão na perspectiva do desenvolvimento socioeconômico local e regional”. (BRASIL, 2008)

É necessário tornar a mulher consciente de seu papel na sociedade, das políticas públicas que possam atendê-la e ser multiplicadora desses conhecimentos para mulheres que estejam em condições semelhantes. Ao se ter este conhecimento, a mesma empodera-se e ganha autonomia, não só nas questões públicas, mas também no âmbito familiar, no trabalho e nas relações sociais (SERPA et al., 2013).

As desigualdades de gênero e raciais afetam a população no acesso à educação, na inserção no mercado de trabalho e na distribuição de renda. Logo, deve ser considerado na construção de políticas públicas que visem ao combate à pobreza, à exclusão digital e combate às violências. Projetos que visam possibilitar alterações na conformação da distribuição desigual socioeconômica, cultural e política são fundamentais para a sociedade.

Autores como Wiley e Rappaport (2000) defendem que empoderar é possibilitar que os indivíduos se insiram em processos sociais e políticos. Sendo assim, propiciar maior autoconhecimento acerca das próprias potencialidades, ensinar o uso de novas ferramentas e propor novas perspectivas sobre a realidade social para reflexão sobre onde estamos e para onde vamos, pode ser considerado uma ação de promoção do empoderamento proposto pelo projeto.

O projeto de extensão "Empoderamento Feminino através da geração de renda pelas vendas" teve como objetivo capacitar um grupo de mulheres em situação de vulnerabilidade social no subdistrito de Pirituba da cidade de São Paulo, que engloba os bairros Jaraguá, Pirituba e São Domingos, para que elas consigam ter, cada vez mais, uma posição significativa no meio em que vivem, melhorando as suas condições de sobrevivência e de sua família. No subdistrito de Pirituba, há de $15 \%$ a 29,9\% da população em situação de alta vulnerabilidade e que reside

Revista Extensão \& Cidadania, v. 9, n. 15, p. 46-63, jan./jun. 2021.

ISSN 2319-0566 DOI: 10.22481/recuesb.v9i15.8638 
em favela, em relação à população do distrito que possui 437.592 habitantes (REDE NOSSA SÃO PAULO, 2017).

De acordo com dados do Serviço Brasileiro de Apoio às Micro e Pequenas Empresas (SEBRAE), o distrito de Pirituba possui 3.058 micros e pequenas empresas no setor do comércio, 3473 em serviços e 956 no setor industrial, evidenciando forte potencial de desenvolvimento econômico regional, a partir da formação de profissionais capazes de atuar nesse contexto. Em uma pesquisa realizada no site da empresa de recrutamento Catho para a região metropolitana de São Paulo, foram ofertadas 1.100 oportunidades para a vaga de promotor de vendas com salário médio de $\mathrm{R} \$ 1125,18$.

Este artigo tem como objetivo apresentar a experiência do projeto de extensão e do curso de Promotora de Vendas que realizou a capacitação profissional de um grupo de 25 mulheres dentro do eixo tecnológico Gestão e Negócios, refletindo sobre a atuação de alguns componentes específicos do curso, que visou possibilitar alterações na conformação da distribuição desigual socioeconômica, cultural e política na sociedade ao qual pertencem.

\section{Feminismo e Cidadania}

As mulheres foram por muito tempo excluídas da cidadania por causa dos interesses da comunidade familiar. Ainda hoje, a partir da simples observação de notícias vinculadas aos meios de comunicação, é possível perceber que uma grande parcela de mulheres ainda tem sua cidadania negada, vivendo em condições de extrema pobreza, sendo a elas destinadas apenas deveres e proibições. Parte considerável das mulheres ainda resume sua participação social à responsabilidade no cuidado doméstico e familiar, o que a deixa em desvantagem no mundo do trabalho remunerado, assim como a torna vulnerável fisicamente em relação à violência masculina. Considerando as mulheres mais vulneráveis social e economicamente, estas ainda são mais severamente afetadas pelas condições precárias de vida em ambiente insalubre e poluído, pois as suas responsabilidades domésticas exigem contato permanente e direto com problemas gerados pela escassez ou falta de serviços de água, esgoto, drenagem e coleta de lixo. Ainda assim, as decisões públicas que afetam as mulheres, de modo geral, estão guiadas, na grande maioria, por preferências masculinas e não por necessidades femininas, questões estas frequentemente antagônicas (LISBOA, 2005).

Revista Extensão \& Cidadania, v. 9, n. 15, p. 46-63, jan./jun. 2021.

ISSN 2319-0566 DOI: 10.22481/recuesb.v9i15.8638 
O processo de empoderamento das mulheres visa ao questionamento das relações patriarcais marcadas pela desigualdade de gênero, especialmente no âmbito familiar e no trabalho. Portanto, o empoderamento feminino permeia a busca pela maior autonomia das mulheres em relação aos seus corpos, sua sexualidade, seu direito de ir e vir e a sua busca por independência financeira. A independência financeira, promovida pelo trabalho, que proporcionam o maior poder de compra são fatores importantes neste contexto, pois a pobreza está vinculada ao contexto de "inutilidade social”. Sendo assim, a utilidade do indivíduo para o sistema capitalista vincula-se ao seu potencial produtivo (SARDENBERG, 2006).

\section{Inclusão digital}

A ação de inclusão digital é um processo significativo na vida das pessoas, e pode ser compreendida como um modo de potencializar interações e possibilidades das pessoas se engajarem em dinâmicas sociotécnicas de forma ativa, participativa e propositiva, e construindo novas realidades sociais (BONILLA; OLIVEIRA, 2011). Essas interações podem ser potencializadas por meio das tecnologias da informação e comunicação (TICs), em meio uma sociedade caracterizada pelo conhecimento, trazendo a importância da educação de base e formação continuada a partir dos cenários de aprendizagem e aplicação prática na sociedade (BASILE; RAMIREZ LÓPEZ, 2020).

\section{Metodologia}

O curso foi oferecido como Curso de Formação Inicial ou Continuada (FIC) com carga horária de 160 horas para 25 alunas. No projeto de extensão, foi realizado o curso FIC de Promotora de Vendas, dividida em dois blocos, o Núcleo Comum que compreendia disciplinas como Linguagens; Matemática; Mulheres no Brasil; Saúde da Mulher; Educação Socioambiental e Inclusão Digital, compreendendo uma carga horária de 100 horas. Este eixo formativo teve como pretensão o nivelamento de conhecimentos entre todas as discentes para que pudessem com a disciplina de Linguagens desenvolver um texto básico, realizar um currículo, praticar a leitura de obras escolhidas para o Programa Mulheres no IFSP, em que houve a participação de uma discente do curso de licenciatura em Letras trabalhando com as

Revista Extensão \& Cidadania, v. 9, n. 15, p. 46-63, jan./jun. 2021.

ISSN 2319-0566 DOI: 10.22481/recuesb.v9i15.8638 
alunas do projeto e praticando os conhecimentos adquiridos no curso de Letras com a supervisão de um docente da área.

O Núcleo Tecnológico compreendeu uma carga horária de 60 horas divididas para 4 disciplinas: Técnicas de Vendas; Comunicação Digital para Vendas; Economia para Vendas e Inglês para Vendas. Estas disciplinas trouxeram a compreensão das habilidades necessárias para atuarem no ramo de vendas e promoverem vendas de forma eficiente para alavancarem os negócios das empresas que poderiam atuar ou seus próprios empreendimentos.

A organização e execução do projeto contou com a uma equipe multidisciplinar composta por técnicos e docentes de diferentes áreas do IFSP Pirituba e membros externos. Um módulo era composto por disciplinas destinadas à qualificação profissional e outro por disciplinas destinadas à consolidação da cidadania, ao resgate à autoestima, à inclusão social, digital e cultural, ao combate à violência contra a mulher e ao desenvolvimento sustentável. O objetivo em ambos os módulos era proporcionar as alunas a compreensão do conteúdo conforme a sua realidade e suas experiências pessoais a partir de avaliações diagnósticas. A Tabela 1 apresenta a matriz curricular do curso realizado.

Tabela 1 - Matriz curricular do curso de Curso de Formação Inicial ou Continuada (FIC) de Promotora de Vendas. São Paulo, SP, Brasil, 2019.

\begin{tabular}{|c|c|}
\hline Componente Curricular & Total Horas \\
\hline \multicolumn{2}{|l|}{ Núcleo Comum } \\
\hline Linguagens, Códigos e suas Tecnologias & 20 \\
\hline Matemática Básica & 20 \\
\hline Mulheres no Brasil: Cidadania, Direitos e Luta por Igualdade & 20 \\
\hline Saúde da Mulher & 15 \\
\hline Educação Socioambiental e Sustentabilidade & 5 \\
\hline Inclusão Digital & 20 \\
\hline \multicolumn{2}{|l|}{ Núcleo Tecnológico } \\
\hline Técnicas de Vendas & 20 \\
\hline Comunicação Digital para Vendas & 10 \\
\hline Economia para Vendas & 10 \\
\hline Inglês para Vendas & 20 \\
\hline Carga horária total do curso & 160 \\
\hline
\end{tabular}

Fonte: Dados do projeto, 2019.

Revista Extensão \& Cidadania, v. 9, n. 15, p. 46-63, jan./jun. 2021.

ISSN 2319-0566 DOI: 10.22481/recuesb.v9i15.8638 
A seleção das alunas foi realizada em parceria com a ONG Projetos Amigos das Crianças (PAC) a partir do preenchimento de fichas de interesse e aplicação de questionários socioeconômicos.

Além dos docentes, alguns estudantes voluntários foram selecionados sob supervisão e orientação de professores do campus Pirituba para desenvolvem as atividades planejadas nos componentes curriculares: Linguagens, Códigos e suas Tecnologias; Matemática Básica e Mulheres no Brasil. Foram selecionados alunos dos cursos de Letras, Engenharia de Produção e Tecnologia em Gestão Pública, respectivamente.

Em atenção à diversidade e à especificidade do alunado atendido, foram sugeridos os seguintes instrumentos de acompanhamento e avaliação da aprendizagem escolar: 1) avaliação diagnóstica por meio de diferentes instrumentos, tais como rodas de conversas, testes, provas, questionários etc., visando orientar o planejamento das atividades e o trabalho dos docentes; 2) observação processual e registro das atividades; 3) avaliações escritas em grupo e individual; 4) produção de portfólios e relatos escritos e orais; 5) relatórios de trabalhos e projetos desenvolvidos; 6) instrumentos específicos que possibilitem a autoavaliação (do professor e da estudante); e 7) assiduidade (frequência mínima de 75\%), considerando a frequência diária às aulas teóricas e práticas, aos trabalhos escolares, aos exercícios de aplicação e à realização das atividades. Além das atividades previstas no PPC, foram realizadas oficinas, palestras e minicursos, compreendendo 85 horas nestas atividades. Como exemplo de atividades foram realizadas oficinas de Mapa da vida; Relaxamento e Bem-Estar; Valorização de direito das mulheres; Atividades esportivas; Maquiagem; minicurso sobre Arte para vendas e, por último, Alimentação saudável, além de palestras sobre Violência contra a mulher e Empreendedorismo ministrado pelo SEBRAE.

\section{Resultados e discussão}

Realizou-se uma caracterização socioeconômica do público atendido (Gráfico 1) e das 25 alunas selecionadas; 16 finalizaram o curso, sendo os principais motivos da evasão relacionado a problemas de saúde da aluna ou de algum membro familiar (20\%) e entrada no mercado formal de trabalho durante o curso (12\%). A grande maioria possuía ensino médio completo (46\%) demonstrando a grande heterogeneidade da turma e requerendo estratégias

Revista Extensão \& Cidadania, v. 9, n. 15, p. 46-63, jan./jun. 2021.

ISSN 2319-0566 DOI: 10.22481/recuesb.v9i15.8638 
pedagógicas específicas para nivelamento e aquisição e desenvolvimento de habilidades específicas. Foi importante estimular a interação e o trabalho em grupo, no grupo, $92 \%$ das discentes possuíam filhos e informaram que não tinham uma atividade remunerada, dependendo de programas sociais. Os dados obtidos através da caracterização socioeconômica são interessantes para se perceber que a grande maioria do público atendido pelo projeto é de mulheres pardas com ensino médio e renda familiar inferior a 1 salário-mínimo, condizentes as especificações para participação no curso.

$\mathrm{Na}$ aplicação das oficinas, foram obtidas percepções dos docentes, como a da oficina de Valorização e Direitos das Mulheres, que foi relatada pela docente responsável ter sido uma oportunidade de as estudantes refletirem sobre o papel social do gênero feminino e a insistência em tratá-lo como "inferior", "frágil”, “incapaz", "submisso". A conscientização da historicidade da subjugação das mulheres e a consideração de que se trata de um problema que diz respeito a todas. Este foi o foi o primeiro passo para reflexão de como enfrentá-lo. Foi fundamental permitir que conversassem, trocassem experiências a partir do que as reflexões, leituras e pesquisas suscitaram. Ao socializarem suas descobertas, foi favorecido o despertar de um sentimento de pertencimento a um grupo, cujos direitos e dignidade devem ser intransigentemente defendidos. Segundo a docente Maria de Fatima das Neves Moreira: "aprendemos a ouvir: esta é a maior riqueza que o projeto permitiu. Conhecer as vidas de mulheres comuns é um incentivo".

\section{Gráfico 1 - Caracterização socioeconômica das alunas do projeto}

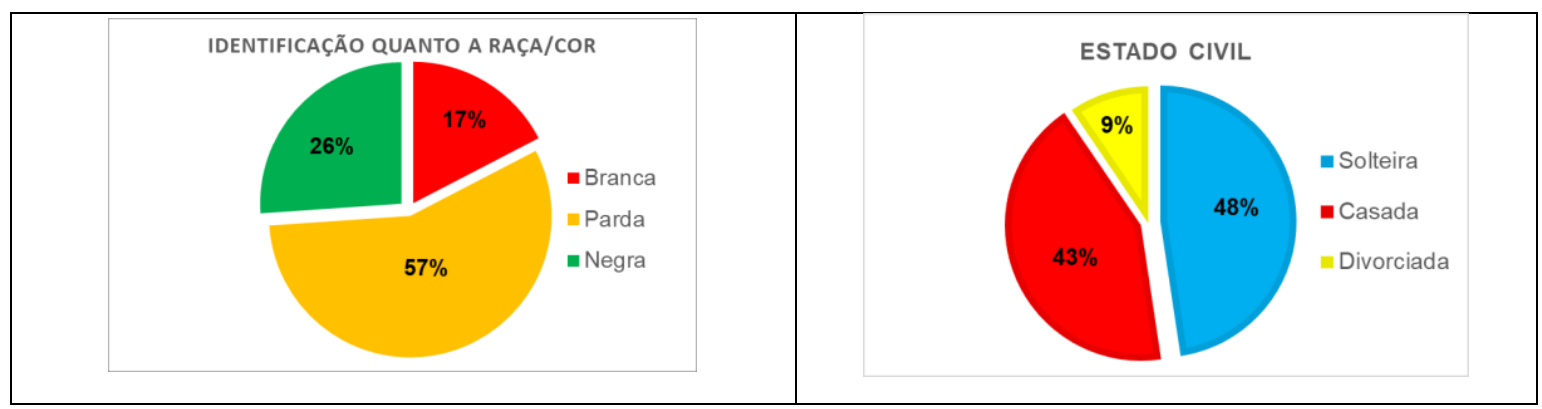

Revista Extensão \& Cidadania, v. 9, n. 15, p. 46-63, jan./jun. 2021.

ISSN 2319-0566 DOI: 10.22481/recuesb.v9i15.8638 


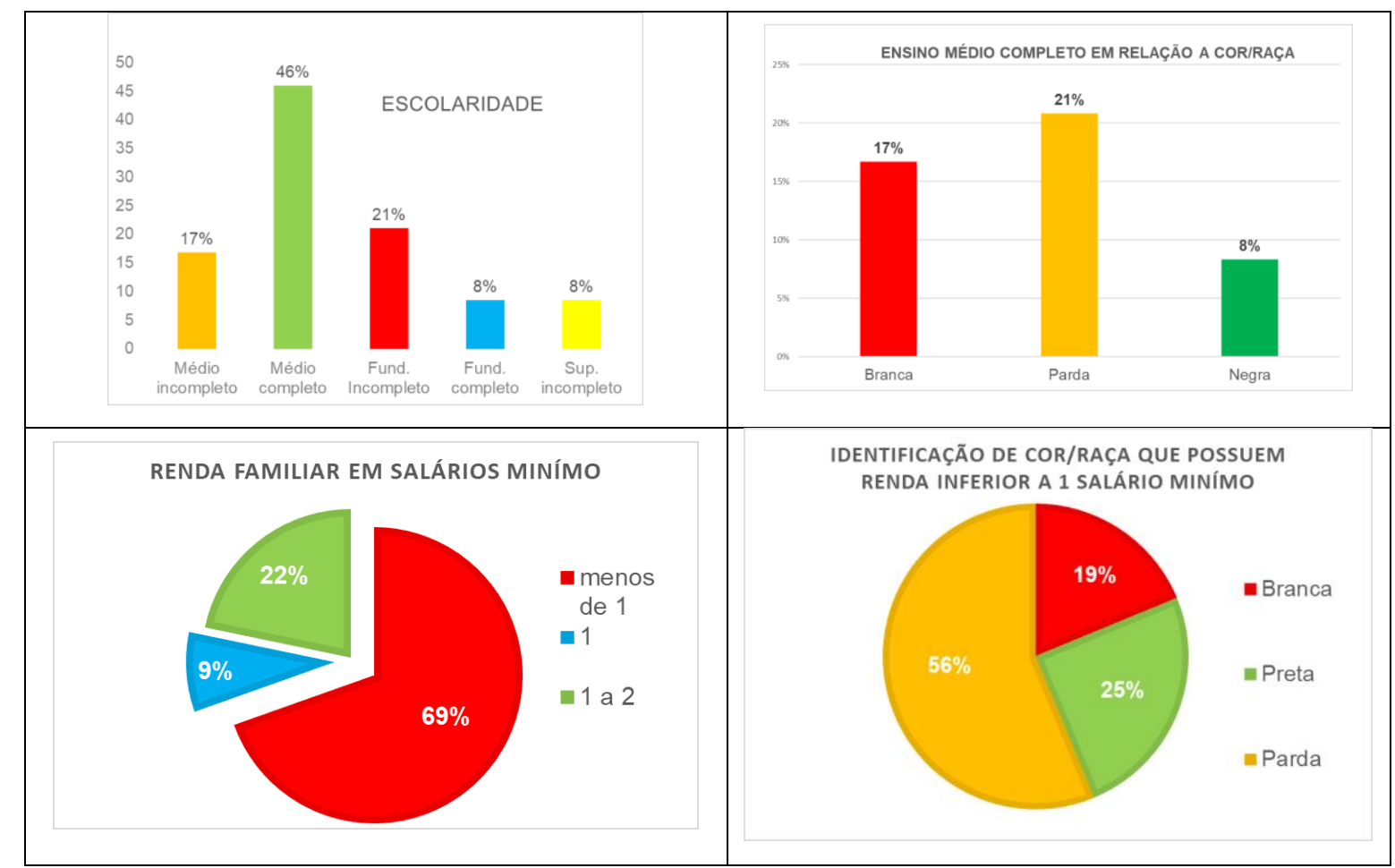

Fonte: Dados do projeto, 2019.

A realização da oficina Mapa da Vida (Figura 1), ofertada pela docente Elisangela Lizardo de Oliveira, como parte de exercício de autoconhecimento e socialização da história de vida de cada uma, foi considerada uma das mais estratégicas para que a equipe do curso conhecesse o perfil da turma e das estudantes individualmente. Foi possível avaliar as expectativas das alunas em relação ao curso e planejar o desenvolvimento das atividades futuras, além de fazê-las refletir criticamente sobre seus objetivos durante e depois do projeto. Segundo Santana et al. (2006), a consciência é primeiro passo para o processo estímulos dos indivíduos na construção das transformações culturais e sociais. Após a vivência, realizou-se uma reunião com a equipe para socialização das informações para conscientização e sensibilização sobre a trajetória das alunas que, em sua maioria, possuía histórias de vida envolvendo questões como abandono e violência.

As oficinas, minicursos e palestras foram ofertadas concomitantemente com o curso FIC de Promotora de Vendas e percebeu-se que era um momento de muita união e troca de experiência entre discentes, docentes e alunos voluntários (Figura 2). Foram exatamente nestas situações a compreensão da importância da extensão como um dos pilares do envolvimento efetivo para a mudança da sociedade, no qual o IFSP está inserido. As oficinas e palestras sobre

Revista Extensão \& Cidadania, v. 9, n. 15, p. 46-63, jan./jun. 2021.

ISSN 2319-0566 DOI: 10.22481/recuesb.v9i15.8638 
Saúde da mulher; Alimentação; Automaquiagem; Direito da mulher e Ginástica também tiveram o resultado esperado, considerando os relatos das estudantes de melhora da autoestima e maior consciência corporal, o que se pode entender como um processo de empoderamento psicológico, não apenas na esfera social e política, mas primeiro pessoal, pois significou a quebra da reprodução de discursos autodepreciativos que as colocavam num papel de merecimento da violência e submissão que já estiveram ou estavam.

Figura 1 - Realização da Oficina Mapa da Vida
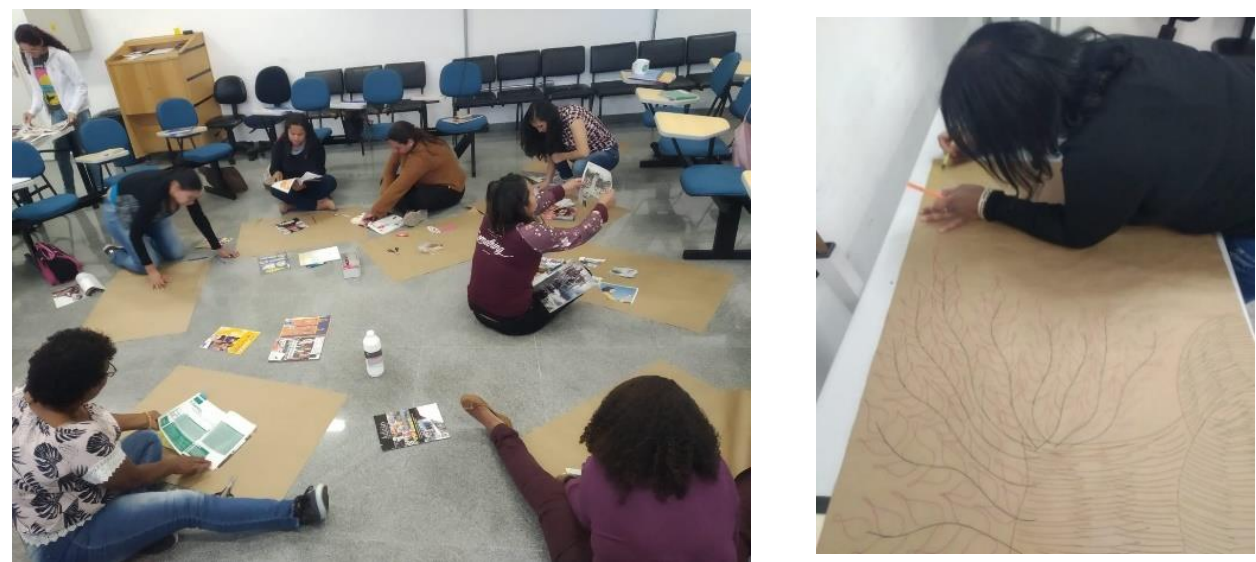

Fonte: Dados do projeto, 2019.

Figura 2 - Ações desenvolvidas durante o Projeto
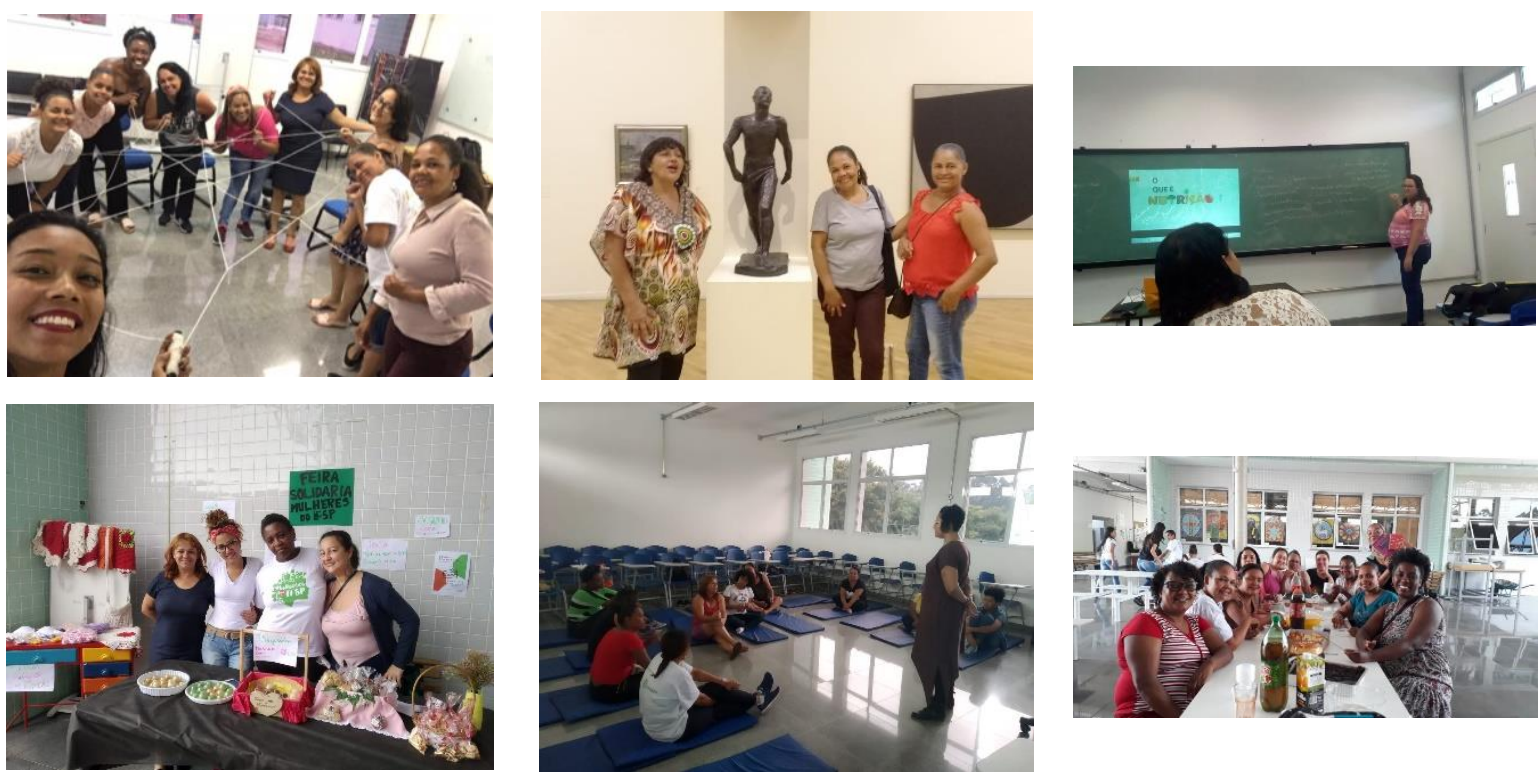

Fonte: Dados do projeto, 2019.

Revista Extensão \& Cidadania, v. 9, n. 15, p. 46-63, jan./jun. 2021.

ISSN 2319-0566 DOI: 10.22481/recuesb.v9i15.8638 
Da mesma forma que ocorreu na disciplina de Linguagens, houve a participação de uma discente do curso de Engenharia de Produção e do curso de Tecnologia em Gestão Pública trabalhando com as disciplinas de Matemática e Mulheres no Brasil (Figura 3). Todas como voluntárias e com a supervisão de um docente da área. O retorno dado pelas alunas do Projeto foi que deveria haver mais estudantes do campus participando do Projeto, pois se sentiram muito acolhidas e em igualdade com as estudantes. Disseram ter aprendido a transmitir o conhecimento adquirido em seus cursos e afirmaram a sua posição de no futuro se posicionarem no mercado de trabalho como docentes e o público-alvo será o adulto.

Figura 3 - Alunas dos cursos de Engenharia de Produção

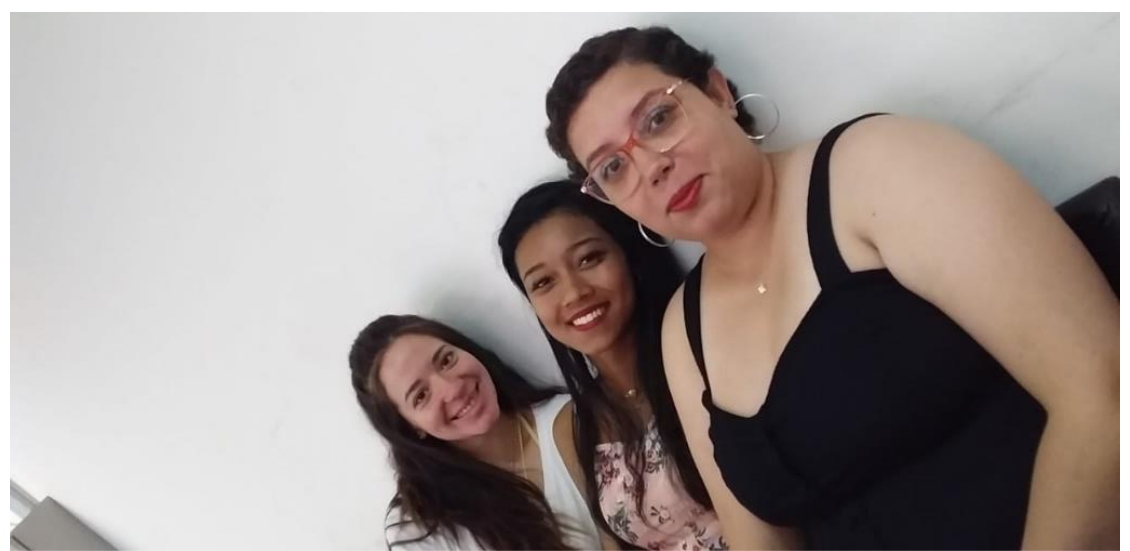

Fonte: Dados do projeto, 2019. (Alicia de Magalhaes Campos, à esquerda), Tecnologia em Gestão Pública (Flora Beatriz Oyama do Patrocínio, ao centro) e Licenciatura em Letras (Bruna Patrícia da Silva Quaglio, à direita).

Uma das disciplinas considerada essencial para o desenvolvimento das alunas no projeto foi a de Inclusão Digital. Nesse sentido, competências e habilidades das alunas foram trabalhadas para realização de atividades práticas, que pudessem contribuir para o empoderamento delas no manuseio do computador, suas partes e outros dispositivos digitais, como o próprio celular.

O processo pedagógico de verificação e avaliação das competências e habilidades, permitiram associação entre teoria e prática em laboratório de informática que, auxiliados por lousa, computadores e softwares modernos, possibilitaram o pleno desenvolvimento tanto de atividades motoras de controle motor fino, como também de atividades cognitivas e desenvolvimento criativo.

Revista Extensão \& Cidadania, v. 9, n. 15, p. 46-63, jan./jun. 2021.

ISSN 2319-0566 DOI: 10.22481/recuesb.v9i15.8638 
Tais atividades visavam permitir, por exemplo, a criação de senhas mais seguras, divulgação de seus produtos/serviços nas redes sociais, envio e recebimento de e-mails, verificação da veracidade das mensagens recebidas pelas redes sociais, dentre outras. Para as aulas desta disciplina foram realizados dez encontros em laboratório de informática, onde houve o desenvolvimento de atividades teóricas e práticas em cenários adaptados para realidade do curso de promoção de vendas.

Houve a interação com recursos de hardware e software com atividades desde ligar e desligar o computador seguindo boas práticas de segurança e de prevenção contra incidentes, passando pela manipulação de arquivos e pastas (criação, edição e exclusão), uso de editores de imagem, navegação na internet, envio de e-mails, planilhas de cálculos com ênfase em orçamento doméstico, despesas e receitas, compras em supermercados e análise de situações práticas, edição de textos aplicando tarefas de digitação e formatação básica para estruturar organização de currículos e outros estilos de documentos (Figura 4).

Figura 4 - Alunas realizando atividades da disciplina de Inclusão Digital
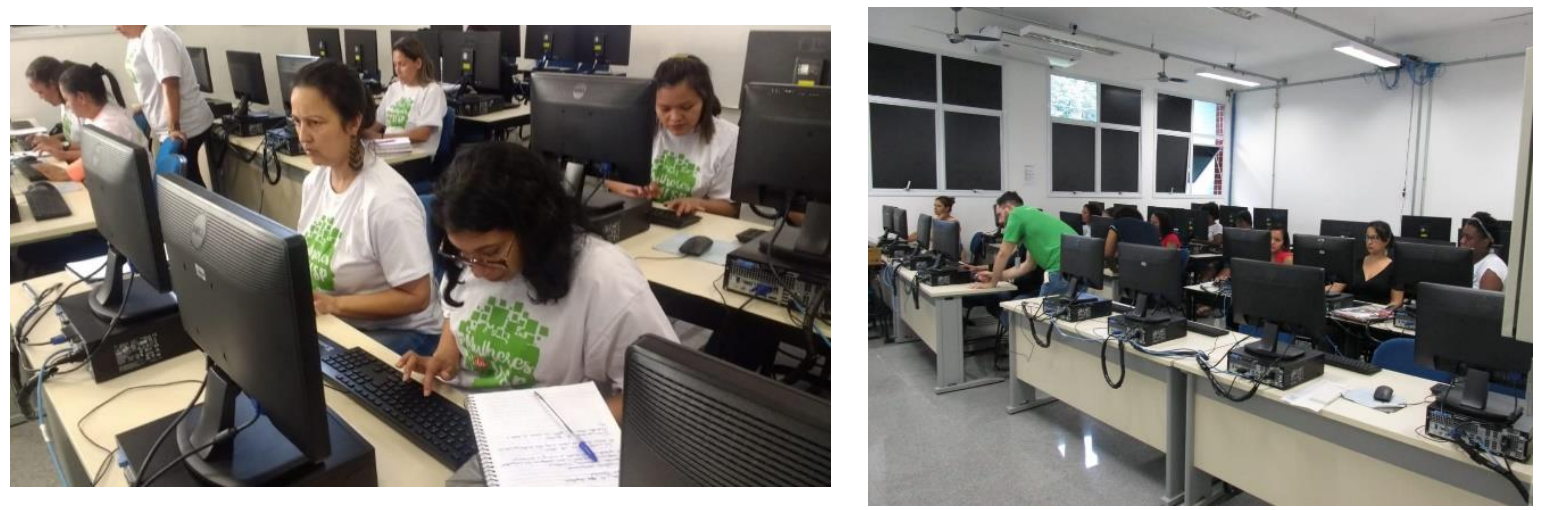

Fonte: Dados do projeto, 2019. Supervisão da atividade pelo Prof. Thiago Homem Donadon.

Por fim, como atividades fundamentais do processo formativo das mulheres, elas tiveram contato com as diversas ferramentas disponíveis gratuitamente na suíte da Google, como Gmail, Documentos do Google e Calendário. Já os Documentos do Google visavam à construção colaborativa de documentos de texto. Encerrando o processo formativo de suítes da Google, foi apresentado o Calendário da Google, discutindo as principais funcionalidades e aplicações no nosso dia a dia. Na Figura 5, estão as estudantes e o professor de Inclusão Digital.

Revista Extensão \& Cidadania, v. 9, n. 15, p. 46-63, jan./jun. 2021.

ISSN 2319-0566 DOI: 10.22481/recuesb.v9i15.8638 
Ao final do estudo da suíte de aplicativos para tarefas de escritório, contextualizadas ao curso de promoção de vendas, as alunas estiveram trabalhando com editor de apresentações. Nessa aula houve a elaboração de slides para apresentação de produtos, marcas e até mesmo contextualização com o aprendizado de edição de imagens. Tudo isso permitiu que as alunas criassem apresentações para tornar a comunicação da mensagem mais eficiente, como por exemplo ao desenvolver uma apresentação utilizando folhas de slides.

Docentes e alunas voluntárias ao final do projeto realizaram algumas considerações sobre a prática do ensino e o que aprenderam ao participar do projeto. O professor Wiliam, da disciplina de Técnicas de Vendas, realizou a seguinte reflexão: "Entre meus aprendizados, poderia elencar: - um melhor balanço entre atividades práticas e leituras/ atividades expositivas são necessárias. As leituras precisam ser curtas. Atividades de simulações de situações reais são bem recebidas."

\section{Figura 5 - Alunas do curso com o professor Felipe Basile de inclusão digital}

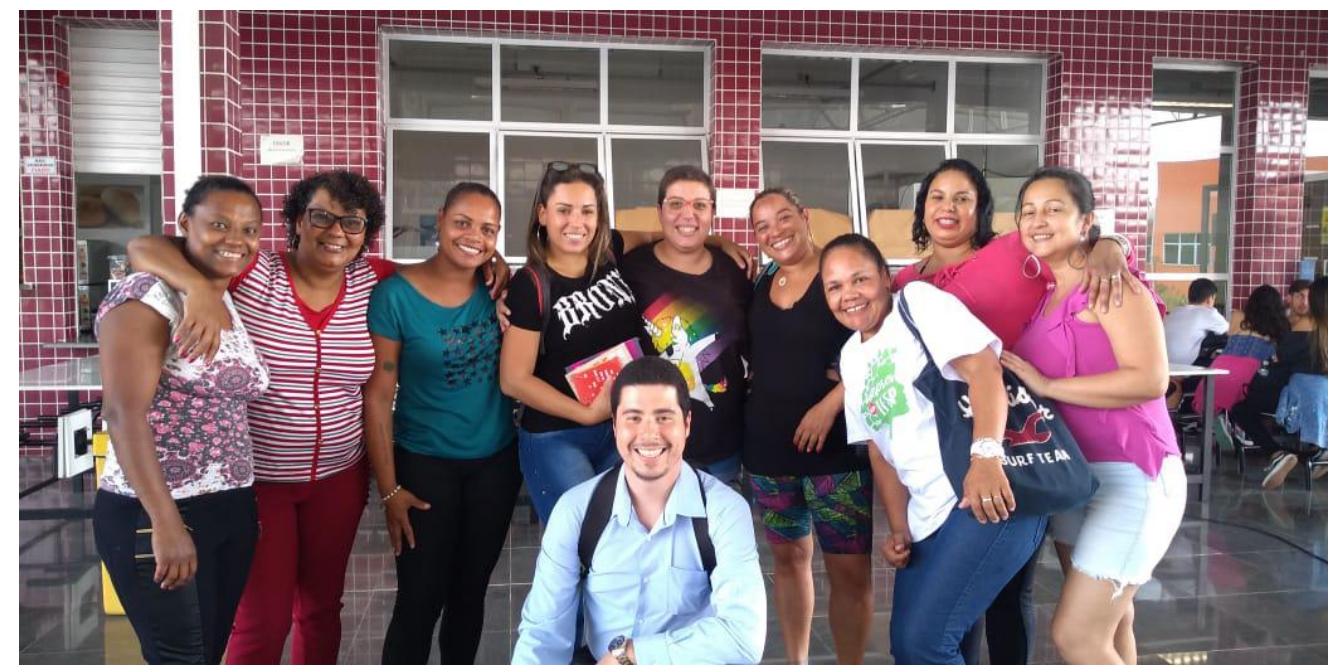

Fonte: Dados do projeto, 2019.

A aluna Alicia de Magalhaes Campos, do curso de Engenharia de Produção, conseguiu refletir sobre sua participação no projeto e do papel que desempenhou ao ministrar a disciplina de Matemática:

Pensando que no dia a dia usamos calculadora, eu ensinei que operações elas poderiam realizar de acordo com a necessidade, exemplificando com situações práticas. Ao conhecer melhor o objetivo e as necessidades de cada uma, direcionei a elaboração dos exemplos em sala e dos problemas nas atividades. Elas estavam muito interessadas em aprender, com muita curiosidade, apesar da dificuldade. O projeto permitiu que eu mergulhasse na realidade dessas mulheres, que é totalmente diferente da minha e eu pude

Revista Extensão \& Cidadania, v. 9, n. 15, p. 46-63, jan./jun. 2021.

ISSN 2319-0566 DOI: 10.22481/recuesb.v9i15.8638 
passar parte do meu conhecimento a elas. Além disso, elas se aproximaram e assim se ajudavam durante as atividades e em questões pessoais. Ao fim do curso, todas nós éramos próximas, desenvolvemos um sentimento recíproco e muito forte. Meu principal objetivo ao me inscrever no projeto era aprender como ensinar outras pessoas, por pretender um dia ser professora. Elas permitiram que eu desenvolvesse essa habilidade, além do crescimento pessoal, por conhecer realidades e pessoas tão distintas.

Professor Felipe Basile da disciplina de Inclusão Digital teve a seguinte percepção final:

A experiência de ministrar o conteúdo programático de inclusão digital para o público-alvo de MULHERES foi muito gratificante. O cuidado necessário para preparação em uma perspectiva de aplicação prática para a promoção de vendas foi bastante interessante. Aprendi que a exclusão social e digital alcança homens, mulheres, crianças e anciãos. As tecnologias estão ao mesmo tempo trazendo facilidades, mas para muitos tem sido um obstáculo quase que intransponível. Procurei escutar as dificuldades de cada uma das alunas e procurei inserir a palavra paciência e trazer um contexto de inclusão, mesmo que as dúvidas se colocaram como básicas e muito simples. Apesar de um grupo heterogêneo, foi importante ouvir cada uma delas com paciência e com bom trato, lembrando da missão de incluir digitalmente as alunas em suas necessidades práticas e, ao mesmo tempo, trazer novas interações dentro do atendimento do conteúdo programático. Utilizei algumas estratégias pedagógicas de situações-problema e do tratamento de mais atenção que já tive em outras experiências de extensão, como por exemplo com os idosos. Aprendi que a motivação extrínseca por mim ministradas em ambiente de laboratório de informática foi fundamental, para resgatar o querer, agir e expressar anseios, dúvidas e o novo aprendizado no mundo digital. Compreender as necessidades delas, planejar aulas que fossem objetivas e progressivas no processo de inclusão foi também outro aprendizado. Planejar atividades de criação de artefatos tecnológicos voltados a promoção de vendas tornou meu aprendizado sobre o tema como um aspecto bastante atrativo para minha atividade docente. A adaptação da execução das instruções computacionais para uma breve explicação, atendimento aluna a aluna dentro do tempo de aula foi também um grande desafio que cumpri, e consegui otimizar ao longo das aulas. Por fim, analiso essa oportunidade de crescimento e evolução profissional mesmo ministrando aulas no curso técnico, extensão e graduação. Espero que possa ter contribuído com a evolução das alunas, ao mesmo tempo que eu possa ter compreendido o quão importante é doar-se para inclusão digital das pessoas em um mundo que se torna cada vez mais conectado e sintetizado a troca de informação cada vez mais rápidas e impactantes. Agradeço a toda equipe de docentes e discentes bolsistas que se integraram e puderam compartilhar de suas experiências para que eu pudesse agregar as minhas aulas todo o cuidado e toda atenção possível.

A aluna voluntária Flora Beatriz Oyama do Patrocínio, do curso de Tecnologia em Gestão Pública, trouxe o seguinte relato:

Lecionar nesse curso foi uma das experiências mais significativas da minha vida, desde a preparação de aulas, as discussões em classes e a correção das atividades. Saber que pude contribuir com o aprendizado dessas mulheres é gratificante. Eu ensinei e fui ensinada, conhecimentos que perpassam a sala de aula. A experiência foi, sem dúvidas, engrandecedora para minha formação acadêmica.

A aluna voluntária do curso de Licenciatura em Letras, Bruna Patrícia da Silva Quaglio, refletiu sobre sua participação:

Eu aprendi mais do que ensinei nesse período, cada uma com sua história de vida e suas superações, me ensinaram muito sobre não desistir e sempre se superar. Pude pensar sobre o tipo de profissional que

Revista Extensão \& Cidadania, v. 9, n. 15, p. 46-63, jan./jun. 2021.

ISSN 2319-0566 DOI: 10.22481/recuesb.v9i15.8638 
quero ser, pensar sobre o caminho que desejo seguir e como a profissão-professor pode impactar na vida das pessoas, em como a força de vontade de estudar muda vidas. Essa experiência me reforçou que estou no curso certo e vou seguir cada vez mais nesse caminho, com o objetivo de dar aula em EJA.

Para finalização da execução do projeto, houve a cerimônia de formatura que, para estas mulheres, foi a concretização de um sonho antes somente visto em telas de cinema, mostrando para elas que a educação pode realizar muitos planos (Figura 6).

Figura 6 - Cerimônia de formatura com as alunas do curso, alunas voluntárias, bolsista, equipe do projeto e ONG PAC

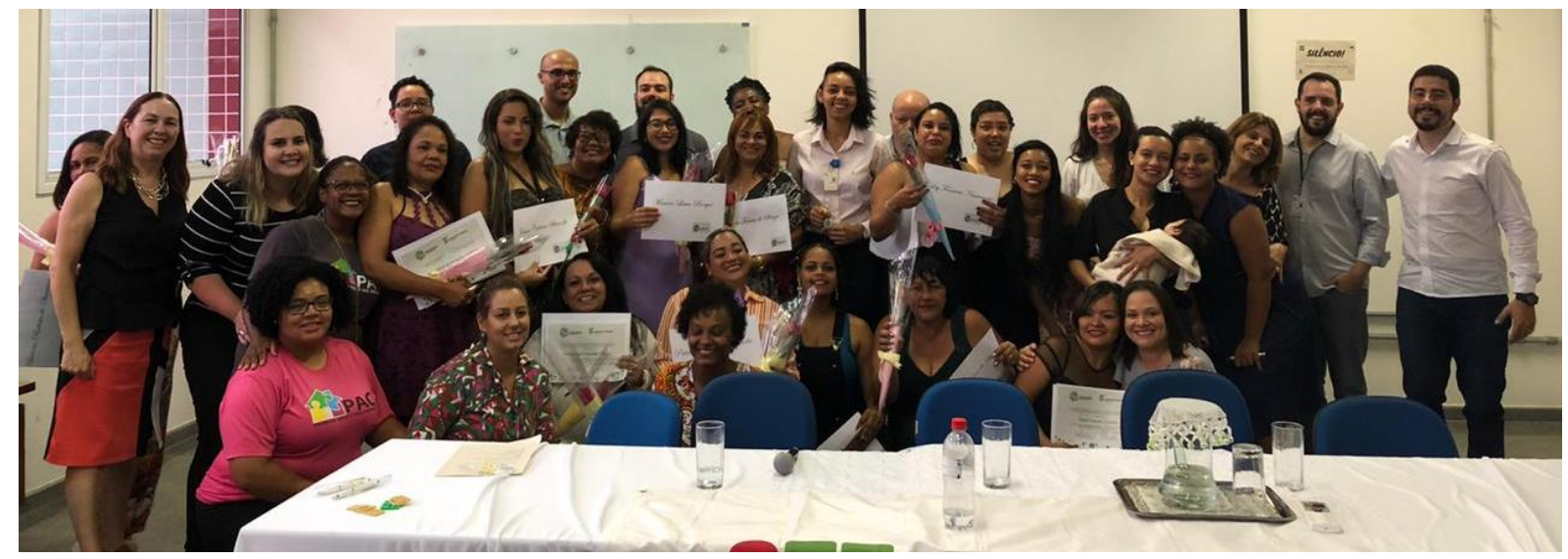

Fonte: Dados do projeto, 2019.

\section{Considerações finais}

A realização deste Projeto atingiu o objetivo de capacitar um grupo de mulheres em vulnerabilidade social apesar de não ter atingido $100 \%$ do grupo de 25 mulheres, pois houve a evasão de $35 \%$ das alunas, cujos principais motivos foram problemas pessoais e familiares, e algumas conseguiram uma posição de trabalho. Mas dentro daquilo que foi proposto, como trazer informação e conhecimento para as alunas, romper o ciclo da violência, elevar a autoestima do grupo, é possível afirmar que obtivermos $100 \%$ de resultado esperado.

A formação oferecida serviu como fonte de emancipação, uma forma de resistência e promoveu o reconhecimento e valorização dessas mulheres. Deste grupo de 16 mulheres que concluíram o curso, 30\% irão prosseguir seus estudos em outras categorias, demonstrando uma mudança significativa no desenvolvimento consciência individual de força e autoconfiança.

Revista Extensão \& Cidadania, v. 9, n. 15, p. 46-63, jan./jun. 2021.

ISSN 2319-0566 DOI: 10.22481/recuesb.v9i15.8638 
As estudantes voluntárias dos cursos de graduação reconheceram que a Extensão tem um papel transformador na vida de quem pratica (principalmente) e na de quem participa. $\mathrm{Na}$ percepção dos docentes e técnicos administrativos, o Projeto trouxe a reflexão de que a comunidade interna tem muito a transmitir para a comunidade externa e devem ser praticadas mais ações de extensão que envolvam todos os integrantes do campus.

Consideramos que, a partir de uma educação emancipadora, essas mulheres se tornarão mais capazes de refletir sobre novas construções sociais. A simples formação para a inclusão das mulheres nos sistemas produtivos pode aumentar a sobrecarga de trabalho feminino, considerando que estas continuam responsáveis pelo trabalho doméstico. Por isso, entendemos que é preciso pensar o desenvolvimento de projetos que não ignorem os contextos sociais e culturais específicos dessas mulheres, pensando inclusão em face da desigualdade de gênero.

Nesse sentido, o tema do projeto realiza o empoderamento e não apenas a formação para vendas e traz como resultado, a concepção da emersão de um processo de ação social no qual os indivíduos tomam posse de suas próprias vidas pela interação com outros indivíduos, gerando pensamento crítico em relação à realidade, favorecendo a construção da capacidade pessoal e social e possibilitando a transformação de relações sociais de poder.

\section{Referências}

BASILE, F. R. M.; RAMÍREZ LÓPEZ, L. J. Estrategia formativa en defensa digital para adolescentes: experiencia en el Instituto Federal de São Paulo. Revista Científica General José María Córdova, v. 18, n. 30, p. 271-287, 2020.

BONILLA, M. H. S.; OLIVEIRA, P. C. S. Inclusão digital: ambiguidades em curso. BONILLA, M. H. S.; PRETTO, N. DL. (Org.). Inclusão digital: polêmica contemporânea [online]. Salvador: EDUFBA, 2011. p. 23-48.

BRASIL. Lei 11.892, de 29 de dezembro de 2008. Institui a Rede Federal de Educação Profissional, Científica e Tecnológica, cria os Institutos Federais de Educação, Ciência e Tecnologia. Brasília, DF, 2008.

PORTAL BRASIL. Mulheres são maioria da população e ocupam mais espaço no mercado de trabalho. 2015. Disponível em: http://www.brasil.gov.br/cidadania-ejustica/2015/03/mulheres-sao-maioria-da-populacao-e-ocupam-mais-espaco-no-mercado-detrabalho. Acesso em: 7 jun. 2021.

LISBOA, T. K. Cidadania e equidade de gênero: políticas públicas para mulheres excluídas dos direitos mínimos. Katálysis, Florianópolis, v. 8, n. 1, p. 67-77, jan./jun. 2005.

Revista Extensão \& Cidadania, v. 9, n. 15, p. 46-63, jan./jun. 2021

ISSN 2319-0566 DOI: 10.22481/recuesb.v9i15.8638 
MATA, V. Como as mulheres podem superar os desafios do mercado de trabalho. 2012. Disponível em: https://www.sbcoaching.com.br/blog/carreira/como-as-mulheres-podemsuperar-os-desafios-do-mercado-de-trabalho/. Acesso em: 7 jun. 2021.

OIT, Organização Internacional do Trabalho. Perspectivas Sociales y del empleo en el mundo: avance global sobre las tendencias del empleo femenino 2018. Genebra: OIT, 2018.

PARADELLA, R. Diferença cai em sete anos, mas mulheres ainda ganham $20,5 \%$ menos que homens. 2019. Disponível em: https://agenciadenoticias.ibge.gov.br/agencianoticias/2012-agencia-de-noticias/noticias/23924-diferenca-cai-em-sete-anos-mas-mulheresainda-ganham-20-5-menos-que-homens. Acesso em: 7 jun. 2021.

REDE NOSSA SÃO PAULO. Mapa da desigualdade 2017. [Internet]. 2017. Disponível em: https://nossasaopaulo.org.br/portal/mapa_2017_completo.pdf. Acesso em: 7 jun. 2021.

SANTANA, M. E. et al. El empoderamiento de las mujeres desde una lectura feminista de la Biblia: el caso de la CODIMUJ en Chiapas. Convergencia. Revista de Ciencias Sociales, v. 13 , n. 40, p. 69-106, 2006.

SARDENBERG, C. M. B. Conceituando "Empoderamento" na perspectiva Feminista. I Seminário Internacional: Trilhas do Empoderamento de Mulheres - Projeto TEMPO', promovido pelo NEIM/UFBA, em Salvador, Bahia, de 5-10 de junho de 2006. Disponível em:

https://repositorio.ufba.br/ri/bitstream/ri/6848/1/Conceituando\%20Empoderamento\%20na\%2 0Perspectiva\%20Feminista.pdf. Acesso em: 7 jun. 2021.

SERPA, C.; MAGALHÃES, D.; CELMER, E. Projeto empoderando mulheres: uma iniciativa de enfrentamento à violência de gênero. Seminário Internacional Fazendo Gênero 10. Florianópolis, 2013. Disponível em:

http://repositorio.furg.br/bitstream/handle/1/5229/1384201353_ARQUIVO_cintiaserpa.pdf?se quence $=1$. Acesso em: 7 jun. 2021.

SORJ, B.; GUEDES, L. E. Exclusão digital: problemas conceituais, evidências empíricas e políticas públicas. Novos estudos - CEBRAP [online], n.72, p.101-117, 2005. ISSN 01013300. Disponível em: http://www.scielo.br/scielo.php?script=sci_arttext\&pid=S010133002005000200006. Acesso em: 7 jun. 2021.

WILEY, A.; RAPPAPORT, J. Empowerment, Wellness and the Politics of Development. The promotion of wellness in children and adolescents. Child Welfare League of America, 2000. p. 59-99. Disponível em: https://psycnet.apa.org/record/2001-00169-003. Acesso em: 7 jun. 2021.

Recebido em: 08.05.2021

Aceito em: 19.06.2021

Revista Extensão \& Cidadania, v. 9, n. 15, p. 46-63, jan./jun. 2021.

ISSN 2319-0566 DOI: 10.22481/recuesb.v9i15.8638 